\title{
Characterising vulnerability of the elderly to climate change in the Nordic region
}

\author{
Timothy R. Carter $\cdot$ Stefan Fronzek $\cdot$ Aino Inkinen $\cdot$ Ismo Lahtinen • \\ Matti Lahtinen · Hanna Mela · Karen L. O'Brien • Lynn D. Rosentrater • \\ Reija Ruuhela $\cdot$ Louise Simonsson $\cdot$ Emma Terama
}

Received: 14 July 2013/ Accepted: 26 May 2014/Published online: 27 September 2014

(c) The Author(s) 2014. This article is published with open access at Springerlink.com

\begin{abstract}
Elderly people are known to be more vulnerable than the general population to a range of weatherrelated hazards such as heat waves, icy conditions and cold periods. In the Nordic region, some of these hazards are projected to change their frequency and intensity in the future, while at the same time strong increases are projected in the proportion of elderly in the population. This paper reports results from three projects studying the
\end{abstract}

Electronic supplementary material The online version of this article (doi:10.1007/s10113-014-0688-7) contains supplementary material, which is available to authorized users.

T. R. Carter $(\bowtie) \cdot S$. Fronzek $\cdot$ H. Mela $\cdot$ E. Terama

Climate Change Programme, Finnish Environment Institute

(SYKE), Box 140, 00251 Helsinki, Finland

e-mail: tim.carter@ymparisto.fi

S. Fronzek

e-mail: stefan.fronzek@ymparisto.fi

H. Mela

e-mail: hanna.mela@ymparisto.fi

E. Terama

e-mail: emma@terama.fi

\section{A. Inkinen}

Environmental Policy Centre, Finnish Environment Institute (SYKE), Box 140, 00251 Helsinki, Finland

e-mail: ainoui@gmail.com

\section{Lahtinen}

Data and Information Centre/Geoinformatics, Finnish

Environment Institute (SYKE), Box 140, 00251 Helsinki,

Finland

e-mail: ismo.lahtinen@ymparisto.fi

M. Lahtinen

Climate Research and Applications, Finnish Meteorological Institute, Box 503, 00101 Helsinki, Finland

e-mail: ultmar@suomi24.fi potential impacts of climate change on elderly people in the Nordic region. An interactive web-based tool has been developed for mapping and combining indicators of climate change vulnerability of the elderly, by municipality, across three Nordic countries: Finland, Norway and Sweden. The tool can also be used for projecting temperaturerelated mortality in Finland under different projections of future climate. The approach to vulnerability mapping differs from most previous studies in which researchers selected the indicators to combine into an index. Here, while researchers compile data on indicators that can be accessed in the mapping tool, the onus is on the users of the tool to decide which indicators are of interest and whether to map them individually or as combined indices.

K. L. O'Brien · L. D. Rosentrater

Department of Sociology and Human Geography, University of Oslo, Box 1096, Blindern 0317, Oslo, Norway

e-mail: karen.obrien@sosgeo.uio.no

L. D. Rosentrater

e-mail: lynn.rosentrater@gmail.com

R. Ruuhela

Climate Service Centre, Finnish Meteorological Institute,

Box 503, 00101 Helsinki, Finland

e-mail: reija.ruuhela@fmi.fi

L. Simonsson

Environment and Health Unit, FOI Swedish Defence Research Agency, 90182 Umeå, Sweden

e-mail: louise.simonsson@foi.se

E. Terama

University College London, Institute for Sustainable Resources, 14 Upper Woburn Place, London WC1H 0NN, UK 
Stakeholders with responsibility for the care and welfare of the elderly were engaged in the study through interviews and a workshop. They affirmed the usefulness of the prototype mapping tool for raising awareness about climate change as a potential risk factor for the elderly and offered suggestions on potential refinements, which have now been implemented. These included adding background information on possible adaptation measures for ameliorating the impacts of extreme temperatures, and improved representation of uncertainties in projections of future exposure and adaptive capacity.

Keywords Climate change impacts - Mapping tool . Exposure - Sensitivity · Adaptive capacity - Mortality . Adaptation $\cdot$ Finland $\cdot$ Scenarios

\section{Introduction}

The objective of this study is to identify and map quantitative measures of vulnerability of the elderly to extreme weather associated with climate change at municipality scale in Norway, Sweden and Finland. The origins of this work arise out of CARAVAN, a collaborative Nordic project. The work has subsequently continued as part of the Finnish-funded MAVERIC and European Commissionfunded MEDIATION projects (see "Acknowledgments" section for full project details).

\section{Extreme weather events and the elderly}

Elderly people are one of the groups that are especially vulnerable to a range of weather-related hazards such as heat waves, icy conditions, cold periods and storms. Even in unexceptional years, it has been estimated that an extra 2,000-3,000 deaths occur on average in Finland each year in the cold season (relative to annual mean mortality), with the great majority among persons aged 65 and older (Näyhä 2005). About 50,000 injuries are recorded annually in Finland during the winter period due to slippery pavement conditions. Although these are most frequent among the 40-60 years' age group, the most serious injuries, such as hip and forearm fractures, primarily affect people older than 70 (Ruuhela et al. 2005; Flinkkilä et al. 2010). Heat wave events can result in significant excess morbidity and mortality among the elderly, mainly attributable to cardiovascular or respiratory failure (Rocklöv and Forsberg 2009; Åström et al. 2013). For example, approximately 55,000 excess deaths were recorded in the 2010 Russian heat wave, primarily among the elderly (Barriopedro et al. 2011). The latter event extended to eastern Finland, with an excess mortality of about 400 recorded nationally in July 2010 (Ruuhela 2012, p 112), while an earlier event in 1972 resulted in about 800 excess deaths in Finland (Näyhä 2005). Similar heat wave excess mortality has also been recorded in Sweden (Rocklöv and Forsberg 2008).

The coping capacity of the elderly to respond to extreme weather can also be limited (e.g., through impaired mobility, isolation, and poor access to health and welfare services, O'Neill et al. 2009). For instance, a failure of basic health and welfare monitoring was a contributing factor in the large numbers of excess deaths (around 70,000) reported during the major heat wave event in western and central Europe in 2003 (Robine et al. 2008; Le Tertre et al. 2006).

Climate change and future extreme weather events

Future climate change is expected to alter the frequency and magnitude of certain types of weather events in the Nordic region. The most recent IPCC assessment of extreme events (Seneviratne et al. 2012) reported high confidence in climate projections for a wider northern European region, based on multiple model-based sources. These projections indicate a very likely increase in frequency of high temperature extremes and decline in frequency of low temperature extremes during the $21 \mathrm{st}$ century, in line with changes already observed (with medium confidence) during the 20th century. Heat waves are likely to be more frequent, longer and/or more intense, though summer changes may be relatively small over Scandinavia. Heavy precipitation events are very likely to increase in winter. In addition, it is likely that there has been a poleward shift in mid-latitude, extra-tropical storm tracks during the last 50 years, with medium confidence that this shift will continue due to future anthropogenic forcings (Seneviratne et al. 2012).

\section{Vulnerability mapping}

The concept of vulnerability is widely applied in climate change research (Patt et al. 2009), but it is framed in contrasting ways (Füssel 2010b; Preston et al. 2011) and its definition has been subject to refinement over time (e.g., Lavell et al. 2012). The most recent definition adopted by the Intergovernmental Panel on Climate Change (IPCC 2012, p 564) is more generic than in previous assessments, describing vulnerability as:

The propensity or predisposition to be adversely affected

One of the most popular devices for portraying vulnerability to climate change is through maps. Vulnerability maps are constructed by first identifying key indicators thought to contribute to the vulnerability of a target system (such as a population, ecosystem or institution) to climate change. Indicators are measured or modelled attributes for 
which spatially distributed data are available for geographical units across a region. Selecting from a variety of techniques to standardise the data, these quantitative indicators may be combined into a vulnerability index, a composite measure that can also be mapped. Examples of such exercises abound in the literature, ranging in spatial scale from global (Yohe et al. 2006; Diffenbaugh et al. 2007; and see review by Füssel 2010b), through continental (Metzger et al. 2008; Greiving et al. 2011; Lung et al. 2013), to national (O'Brien et al. 2004a, b) and subnational (Rød et al. 2012; Swart et al. 2012) studies.

Indicators and indices of vulnerability have been widely reviewed in the literature (e.g., Malone and Engle 2011; Preston et al. 2011; Polsky et al. 2007). Unlike estimates of future climate change impacts, which usually involve formalised modelling of cause-effect relationships between climate determinants and the system affected by climate, vulnerability indices commonly rely upon judgements of causality, where indicators are selected if they are believed (often subjectively) to offer a measure of vulnerability to climate change, and then combined (often arbitrarily) into indices. These "conceptual, methodological, and/or empirical deficiencies" (Füssel 2010a) have led to vulnerability mapping being challenged as a scientifically credible analytical method (see Hinkel 2011).

Notwithstanding these criticisms, it is argued here that there can be a useful role for such mapping, as long as the underlying purpose, data and assumptions are fully transparent to the audience. In the health sector, there have been efforts in recent years not only to present vulnerability indices but also to evaluate their performance in predicting health outcomes (e.g., Reid et al. 2012; Loughnan et al. 2013; Wolf et al. 2014). An indicator mapping approach also lends itself to exploratory analyses of climate change vulnerabilities that may be unrecognised by decisionmakers and/or have been little studied. It is apparent that such cases can occur even in countries with relatively advanced adaptation planning but where disregard or complacency about real risks has hampered systematic research in some sectors (O'Brien et al. 2006). The specific case to be examined concerns the potential impacts of future climate change on the elderly population in the Nordic region-manifest through changes in climatic variability, including weather extremes-and the capacity to ameliorate such impacts through adaptation. While the effects of extreme weather on the elderly have been documented for individual events (see "Extreme weather events and the elderly"), to date there has been little systematic research into the potential implications of climate change for municipal populations that are ageing at varying rates across the Nordic region.

The next section presents the overall approach adopted in the study as well as a description of the analytical

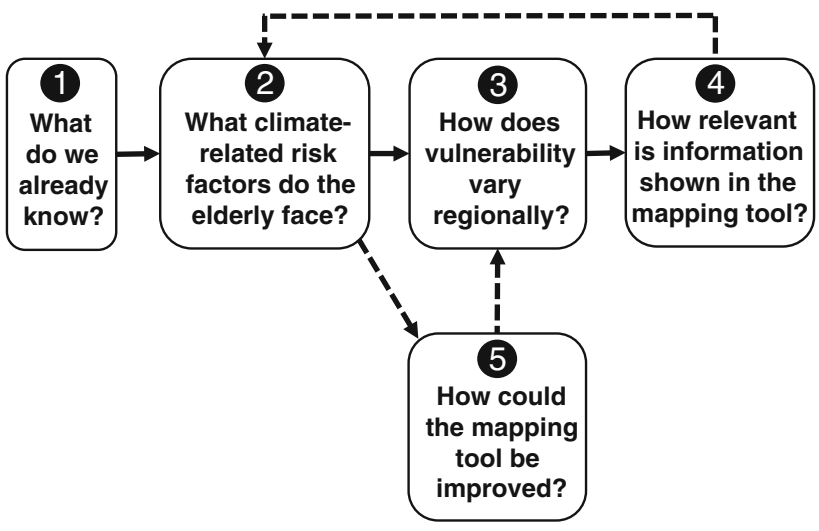

Fig. 1 The five main steps employed in this study, with iterations shown by dashed arrows

methods and data sources used in developing a mapping tool for exploring vulnerability of the elderly to climate change in the Nordic region. The "Results" section outlines different aspects of the mapping tool, illustrating the general set up, input data and their manipulation, some key assumptions, a taste of the types of outcomes that can be generated and some results from stakeholder interaction. The final section then reports some of the lessons learnt from the study and suggests possible future extensions to the mapping tool, offering a number of arguments in support of the approach, tempered with appropriate caveats.

\section{Materials and methods}

\section{Analytical steps}

In common with other case studies undertaken in the MEDIATION project, this assessment can be broken down into a number of analytical steps, each of which may draw on methods associated with general stages of the adaptation learning cycle. Five main steps have been identified by the authors, with a question posed at each step (Fig. 1). These are outlined in more detail in Supplementary Material.

Vulnerability assessment is sometimes framed according to whether it is policy-driven or science-driven (Füssel and Klein 2006), considering whether it is undertaken specifically to inform an impending policy decision or rather as a means to offer scientific evidence for changes that may require policy action (Rothman and Robinson 1997). Under this framing, the initial motivation for the present study in Steps 1-3 can be regarded as science-driven. However, the iterative and participatory nature of Steps 4 and 5 introduce a policy component that is not yet fully realised and might be strengthened in future work (see "Discussion").

The remainder of this paper describes the overall framing, methods and some findings from Steps 2-5. Much 
of the work conducted in the MAVERIC and MEDIATION projects was carried out as the iteration from Step 4, via Step 2, to Step 5, focusing on Finland but also refining the Nordic-wide analysis initiated during the earlier CARAVAN project (Steps 1-4).

Impacts, adaptation and vulnerability

The paper presents two approaches for representing potential impacts of the elderly to future climate change in the Nordic region and possible options for adaptation. The first approach (Step 3 in Fig. 1) is indicative, based on the identification, mapping and combination of variables (indicators) believed to predispose the elderly to adverse impacts. The second approach (added in Step 5) is definitive, focusing on an extreme metric of climate change impact on the elderlypremature mortality-and modelling its dependence on temperature. Hence, the former approach characterises potential vulnerability to adverse impacts, while the latter describes realised vulnerability in terms of one type of adverse impact. In "Box 1" an attempt is made to reconcile these "vulnerability" and "impact" approaches by expressing both as a function of exposure and sensitivity to climate change, each of which can be mediated by adaptation.

Two further aspects of projecting impacts that are also explored in this paper, though commonly overlooked in many other studies, are the characterisation of future socioeconomic conditions (i.e., trends that might themselves influence future vulnerability and impacts regardless of future climate change) and the representation of uncertainty in impact projections (using both scenarios and probabilistic representations).

Vulnerability mapping for the Nordic region

The conventional framing of vulnerability to climate change-as a function of exposure, sensitivity and adaptive capacity ("Box 1", Eq. 4) formed the basis for a series of vulnerability mapping exercises that were initiated at the turn of the millennium. Among these was a study exploring vulnerability to climate change at different scales in Norway (e.g., O'Brien et al. 2004b, 2006). The outputs of that work included a number of mapped indices combining variables identified as important for the exposure and adaptive capacity of Norwegian agriculture (O'Brien et al. 2006) and sensitivity of winter tourism (Sygna et al. 2004) to climate change.

In a follow-up study of climate change vulnerability for the Nordic region (CARAVAN-Carter et al. 2011), the same approach was adopted to map indicators of vulnerability at the municipality scale for Norway, Sweden and Finland. The main rationale for extending this analysis was that the challenges of climate change are similar across the different countries and might warrant a regional approach to strategies of adaptation response. A web-based, interactive mapping tool was developed for depicting vulnerability indicators and allowing these to be combined by a user into composite indices (http://www.iav-mapping.net/ U-C-IAV). Here we concentrate on the development of the tool as it applied to vulnerability of the elderly.

\section{Vulnerability indicators}

A literature review on the vulnerability of elderly people to adverse effects of the weather was undertaken to provide some background information for the selection of indicators. Factors thought to affect exposure, sensitivity and adaptive capacity were treated separately.

Factors affecting exposure Some of the key weather hazards that contribute to exposure of the elderly to possible adverse impacts were discussed in "Extreme weather events and the elderly" and "Climate change and future extreme weather events", above. Numerous indicators of significant (not necessarily extreme) weather events exist in the literature (e.g., Frich et al. 2002; Beniston et al. 2007; Seneviratne et al. 2012), and for the purposes of this study three classes of hazard associated with known impacts on the elderly were defined: exposure to heatrelated events, to cold-related events and to icy conditions. Candidate indicators were then identified for which both observations and projections of future changes were available across the Nordic region. Exposure to climate change was described as the change in frequency of events between 30-year periods (to capture the statistical properties of the weather) at the present and in the future (around 2040). This required information both on observed and projected climate (see "Projecting future vulnerability" section, below). Some changes in climate imply a reduced risk of hazardous weather (for example, projections show a declining frequency of cold spell days in most regions). In such cases, the exposure indicator is negative, as shown in the absolute values of the changes.

A second dimension of exposure is the population at risk of impact. Here, the elderly population was defined according to official national criteria as persons aged 65 and over in Sweden and Finland (67 in Norway). As the proportion of the elderly in the population is expected to increase rapidly in the future, detailed regional projections of population were also required. Note that in the original CARAVAN study, the elderly population was considered as an indicator of adaptive capacity, along with all other socioeconomic variables. However, it has been re-assigned as an exposure indicator in the present study, in line with most earlier interpretations (e.g., von Schirnding 2002; Nicholls et al. 2008). 
Factors affecting sensitivity Some of the important factors contributing to the present-day sensitivity of elderly people to harm from common hazards, including weatherrelated events have been catalogued by OECD (2006) and O'Brien and Leichenko (2007). They include: age (i.e., the progressive loss of psychological resilience with increasing age), deterioration of health (e.g., cognitive and visual impairment, medical drug use), personal lifestyles (e.g., insufficient physical exercise, inappropriate assistive devices), poorly designed and inadequate infrastructure (e.g., building materials, density and accessibility; green spaces), loneliness (including isolation and inadequate social networks), poverty (affecting the ability, willingness or wherewithal to maintain a safe living environment), and inadequate health or social structures (limiting preventative or remedial interventions).

Factors affecting adaptive capacity Finally, factors affecting the adaptive capacity to ameliorate adverse impacts in the future have also been identified (OECD 2006; O'Brien and Leichenko 2007; Koppe et al. 2004): uncertainties regarding the future health care provision of the elderly, level of participation of elderly people in economic activity (i.e., risks associated with their enhanced physical and cognitive impairments compared to younger employees), future welfare and income, patterns of care, and changes in the private sphere (e.g., family relations, divorce rates, childlessness and single households). Adaptive capacity is distinguished from sensitivity in this study with the latter referring to the present-day susceptibility of the population to hazards, while the former relates to those potential adjustments that could reduce future sensitivity and/or exposure.

Selecting the indicators Using the above factors as a guide, a candidate set of indicators of vulnerability was compiled for which spatially distributed information could be obtained or derived. Several criteria were then used to select from the longer list of variables identified:

- availability of observed, statistical (sampled), or modelbased data collected at or interpolated to municipality scale;

- data representing present-day and, if possible, future conditions;

- relevance of the indicator in all three Nordic countries;

- availability of comparable data across all three countries: Finland, Norway and Sweden.

In addition, it was decided to merge sensitivity with exposure in developing the mapping tool. Since the focus is on vulnerability to climate change, for the purposes of this study a simple assumption is made that sensitivity of the elderly exposed to weather events in the future remains unchanged from that at the present-day. Of course, this is unlikely to be the case in reality, as the fitness and general resilience of the population in the future is likely to improve, as it has historically. However, such tendencies are assumed to be captured adequately by the indicators of adaptive capacity. The final set of indicators applied in the study, along with their primary sources, are hence classified either as indicators of exposure/sensitivity (denoted by $\left.E^{*}\right)$ or of adaptive capacity $\left(A^{*}\right.$-Table 1$)$.

Refinements have been made to the data and to their sources for some of these indicators (primarily for Finland) in the MAVERIC and MEDIATION projects. These are described in "Projecting future vulnerability" section, below.

\section{Web-based vulnerability mapping tool}

The tool developed for mapping vulnerability indicators was conceived with the following aims in mind:

- to be accessible publicly through the internet;

- to store geographically referenced administrative boundaries and information for the different indicators listed in Table 1 in an online database;

- to display information accessed from the database as maps across the three Nordic countries at administrative scales ranging from national to municipal, along with various zoom, pan and point interrogation features;

- to provide an interface that allows users to select from the available indicators listed and map these individually, in their original measurement units, across the Nordic region;

- to offer options to select, weight and combine indicators into composite indices of exposure/sensitivity $\left(E^{*}\right)$ or adaptive capacity $\left(A^{*}\right)$, which can also be mapped;

- to facilitate parallel display of $E^{*}$ and $A^{*}$ indicators and indices;

- to compute a vulnerability index that is produced automatically from any combination of user-selected $E^{*}$ and $A^{*}$ indicators and/or indices;

- to provide clear yet comprehensive supporting documentation explaining the functions of the tool, via clickable information and help buttons.

Most present-day and some future demographic and socioeconomic statistics were obtained by municipality. Some data were available only for coarser-scale regions. The climate data for the exposure/sensitivity indicators were generated on a regular grid. Values for municipalities were obtained by averaging the grid cell values that cover a municipality's area.

In order to combine several indicators into composite indices of $E^{*}$ and $A^{*}$, it is necessary to adjust them to 
Table 1 Indicators of exposure/sensitivity and adaptive capacity for characterising vulnerability of the elderly to climate change

\begin{tabular}{|c|c|c|c|c|}
\hline Indicator & Units & Description & Effect & Source \\
\hline \multicolumn{5}{|l|}{ Indicators of exposure/sensitivity $\left(E^{*}\right)$} \\
\hline \multicolumn{5}{|l|}{ Potential heat stress } \\
\hline Change in no. high temperature days & Days/year & $\begin{array}{l}\text { Change by } 2030-2049 \text { in the number of days with daily mean } \\
\text { temperature above the } 99 \text { th percentile observed locally in } \\
1971-2000\end{array}$ & + & $a, b$ \\
\hline Change in no. very warm days & Days/year & $\begin{array}{l}\text { Change in the number of days between } 2030-2049 \text { and } 1971-2000 \\
\text { with daily maximum temperature above } 25^{\circ} \mathrm{C}\end{array}$ & + & $a, b$ \\
\hline Relative change in no. heat waves & Scalar & $\begin{array}{l}\text { Number of heat waves in } 2030-2049 \text { as a proportion of the number in } \\
1971-2000 \text {. A heat wave is defined if the local daily mean } \\
\text { temperature exceeds the 99th percentile observed in 1971-2000 } \\
\text { over an interval of at least six consecutive days }\end{array}$ & + & $a, b$ \\
\hline \multicolumn{5}{|l|}{ Potential cold stress } \\
\hline Change in no. cold days & Days/year & $\begin{array}{l}\text { Change by } 2030--2049 \text { in the no. days with daily mean temperature } \\
\text { below the } 1 \text { st percentile observed locally during } 1971-2000\end{array}$ & + & $\mathrm{a}, \mathrm{b}$ \\
\hline Change in no. cold spell days & Days/year & $\begin{array}{l}\text { Change in the number of days per year contributing to cold spells } \\
\text { between } 1971-2000 \text { and } 2030-2049 \text {. A cold spell is defined as a } \\
\text { period when the local daily mean temperature is below the } 1 \text { st } \\
\text { percentile observed in } 1971-2000 \text { for at least six consecutive days }\end{array}$ & + & $\mathrm{a}, \mathrm{b}$ \\
\hline \multicolumn{5}{|l|}{ Potential icy conditions } \\
\hline Change in no. freezing point days & Days/year & $\begin{array}{l}\text { Change in the number of days when daily minimum temperature } \\
<0^{\circ} \mathrm{C}<\text { daily maximum temperature }\end{array}$ & + & $a, b$ \\
\hline \multicolumn{5}{|l|}{ Elderly population } \\
\hline Present-day & $\%$ & $\begin{array}{l}\text { Elderly persons (age } \geq 65 \text { years in Finland and Sweden; } \geq 67 \text { years in } \\
\text { Norway) as a percentage of the total present-day population }\end{array}$ & + & $\mathrm{c}$ \\
\hline Future & $\%$ & $\begin{array}{l}\text { Elderly persons (age } \geq 65 \text { years in Finland and Sweden; } \geq 67 \text { years in } \\
\text { Norway) as a percentage of the total population projected }\end{array}$ & + & $\mathrm{d}, \mathrm{e}$ \\
\hline \multicolumn{5}{|l|}{ Indicators of adaptive capacity $\left(A^{*}\right)$} \\
\hline \multicolumn{5}{|l|}{ Economic } \\
\hline $\begin{array}{l}\text { Elderly welfare recipients (present- } \\
\text { day) }\end{array}$ & $\%$ & Proportion of the elderly receiving welfare payments & - & $\mathrm{f}, \mathrm{i}$ \\
\hline \multicolumn{5}{|l|}{ Social } \\
\hline Elderly living alone (present-day) & $\%$ & Proportion of the total population that is elderly and living alone & - & $\mathrm{g}, \mathrm{i}$ \\
\hline Health care personnel (present-day) & $\begin{array}{l}\text { Rel. } \\
0-100\end{array}$ & $\begin{array}{l}\text { Number of health care personnel: Finland (health care personnel per } \\
1000 \text { inhabitants by sub-region); Norway (labour years for public } \\
\text { sector doctors per } 10000 \text { inhabitants); Sweden (working public } \\
\text { doctors per } 100000 \text { inhabitants by county) }\end{array}$ & + & $\mathrm{h}, \mathrm{i}$ \\
\hline Home health care (present-day) & $\%$ & $\begin{array}{l}\text { Number of recipients of home health services: Finland (elderly in } \\
\% \text { ); Norway (per } 1000 \text { persons); Sweden (elderly per } 1000 \\
\text { inhabitants) }\end{array}$ & - & $\mathrm{h}, \mathrm{i}$ \\
\hline
\end{tabular}

a Observed climate-European 15 min E-OBS version 8.0 (Haylock et al. 2008) and Finnish 10 km (Venäläinen et al. 2005, updated) gridded daily datasets

b Probabilistic climate projections for the Nordic region (Harris et al. 2010)

c Statistics Finland data for 2009; Statistics Norway data for 2008; Statistics Sweden data for 2008

d Projections for 2030 (Nordic)—National Institute for Health and Welfare (Finland), 2009; Statistics Norway, 2006; National Board of Health and Welfare (Sweden), 2008

e Probabilistic projections for 2040 (Finland-Terama et al. 2014)

f Data for 2008 (Statistics Finland; Statistics Norway and Statistics Sweden)—standardised across countries

g Statistics Finland data for 2009; Statistics Norway data for 2009; Statistics Sweden data for 2008

h National Institute for Health and Welfare (Finland) data for 2007; Statistics Norway data for 2006; National Board of Health and Welfare (Sweden) data for 2008; values standardised across all three countries

i Projections for 2040 (Finland only) based on extrapolation of historical time series (Terama et al. 2014) 
standard units through a normalisation procedure. In this study linear scaling was applied to values for each municipality relative to the municipality range, where the minimum value is assigned a value of 0 and the maximum a value of 1 . Composite indices are produced by averaging the normalised values. These computations are carried out automatically, as soon as multiple indicators have been selected. Differential weighting of individual indicators can also be applied (up to a weighting factor of 10). Note that some indicators are listed as alternatives for representing a single risk factor. For example, in Table 1 three indicators of potential heat stress are listed, but only one can be selected at a time, to avoid over-representing heat stress in a situation where multiple stresses are being combined in a composite index (e.g., of heat stress, cold stress and icy conditions).

Vulnerability indices can be depicted as a combination of normalised $E^{*}$ and $A^{*}$ indicators. High values of $E^{*}$ contribute to high relative vulnerability. In contrast, high values of $A^{*}$ reduce the level of relative vulnerability. A vulnerability index $(V)$ can then be calculated as an exact formulation of the function in Eq. 4 ("Box 1"):

$V=\left[E^{*}+\left(1-A^{*}\right)\right] / 2$.

On the mapping tool, once values have been specified and mapped for $E^{*}$ and $A^{*}$ in adjacent panels, values are computed according to Eq. $4 \mathrm{~b}$ and mapped automatically on a third panel alongside the other two (see Fig. 2).

For compositing, normalisation is applied to indicators of exposure to climate change regardless of their sign. This means that regional exposure is depicted in relative terms from low to high, without distinguishing whether future climate-related risk increases or decreases. In order to identify regions in which one or more indicators shows a future decline in risk, stippling appears in addition to colour shading on both the exposure and vulnerability maps.

\section{Projecting future vulnerability}

The prototype CARAVAN tool included projections for only a subset of indicators (climate-based and population) and for each of these only a single projection was offered. Adaptive capacity indicators were provided only based on present-day statistics. Two aspects of future vulnerability were explored during revision of the tool (Step 5, Fig. 1): scenarios of adaptive capacity and considerations of uncertainty in projections.

Scenarios of adaptive capacity Upper and lower bounds on plausible future trends in the adaptive capacity indicators were defined for Finland, based on extrapolations of historical time series over aggregated regions (Terama et al. 2014). They are designed to convey the inherent uncertainty in each of the indicators and were selected to provide options for exploring the sensitivity of vulnerability indices to different assumptions about future adaptive capacity and to compare with using present-day values (the trend terms in Eq. 7, "Box 1"). In addition to representing future uncertainty, the range in these indicators can help to reveal possibilities for improving capacity as well as comparing status and progress across regions or countries.

Uncertainties in projections Uncertainty ranges were specified for the exposure/sensitivity indicators, making use of probabilistic projections of both climate and population. For climate, this involved multiple adjustments of observed daily temperatures, sampling across a range of model-derived, probabilistically generated projections for the Nordic region assuming the SRES A1B emissions scenario (Harris et al. 2010). For mortality modelling, a sampling was undertaken of general circulation model (GCM) projections over Finland, ranging from low-end (5 percentile) warming under the SRES B1 low emissions scenario (surrogate for an aggressive mitigation scenario), to a high-end (95 percentile) A2 high emissions scenario (Jylhä et al. 2009). This allows users to explore how climate change mitigation might contribute to reducing impacts (Eq. 7, "Box 1"). Climate projections are for 2030-2049 (vulnerability mapping) and 2020-2049 (mortality modelling) relative to 1971-2000.

Population projections, like climate projections, are also subject to large uncertainties. Here probabilistic population projections for Finland were generated using the program for error propagation (Alho and Spencer 1985), focusing on the two largest sources of error in population forecasting: mortality and migration. The model error parameters and sources of population forecasting errors in general are discussed in detail by Alho and Spencer (1997). Projections extend out to 2040, and are for NUTS-2 administrative regions of Finland. More details are presented in Terama et al. (2014).

\section{Stakeholder engagement}

The key stakeholders being targeted in this study are national and regional officials responsible for the care and welfare of the elderly, including representatives of social and health ministries, national health and welfare research institutes, umbrella bodies for various associations concerned with the welfare of the elderly, rescue and emergency services and organisations concerned with the planning and design of physical infrastructure for the elderly. Two approaches were employed for engaging stakeholders: interviews and a workshop. 


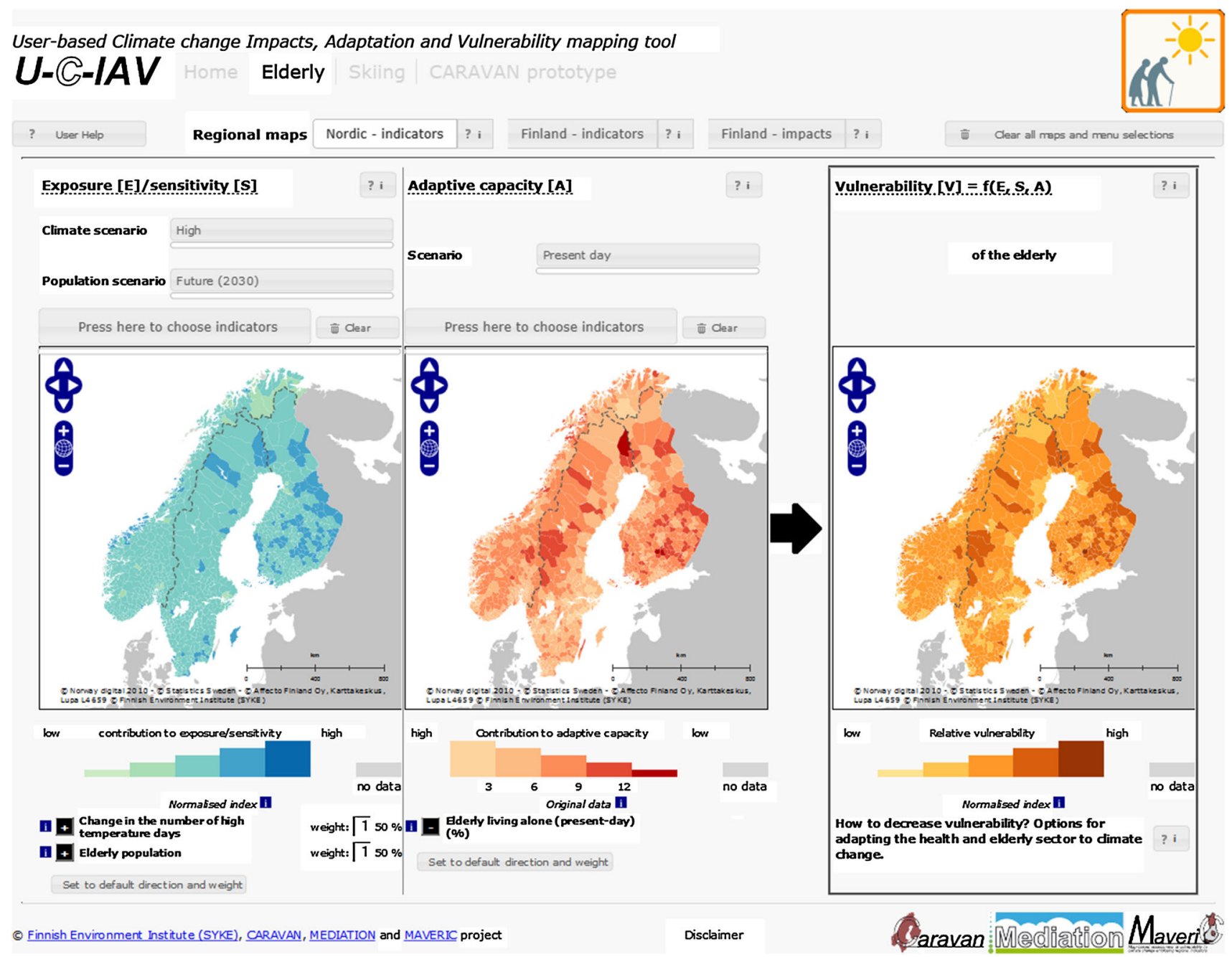

Fig. 2 Screen shot of mapping tool showing a composite exposure/ sensitivity index, combining equally weighted $(50 \%)$ indicators of change in the number of high temperature days (high scenario) and elderly population (2030 scenario) scaled in relative units (left panel), an indicator of adaptive capacity (present-day proportion of elderly

\section{Interviews}

Interviews were conducted with a number of public officials. For this, a set of questions was agreed among the Nordic partners. These included questions on:

- Awareness about the vulnerability of elderly people (their constituents) to the effects of temperature and other weather-related challenges.

- Knowledge and access to information about climate change.

- Opinions on the importance of climate change for public health.

- Understanding of climate adaptation and related measures.

- Knowledge about regional differences in access to health care among the elderly. living alone) in original units (middle panel) and an automatically generated composite of the two into a vulnerability index (right panel). Plus and minus symbols indicate the direction of effect of indicators on their respective composite indices (cf. Table 1). The web tool can be found at http://www.iav-mapping.net/U-C-IAV

- Opinions on public health priorities for the elderly.

- Concerns, if any, about consequences of climate change for the elderly.

Interviews were undertaken in Finland and Sweden during 2010. No interviews could be arranged in Norway, due to a low priority attached to the issue by the experts approached.

\section{Workshop}

A half-day stakeholder workshop was organised in November 2010 at Stockholm University to explore aspects of vulnerability to climate change among the elderly. It brought together CARAVAN and MEDIATION project researchers and Nordic representatives of national and regional organisations who have responsibility for the care 
of the elderly. The two main objectives of the workshop were to stimulate a discussion of climate change vulnerability of the elderly in the Nordic region between researchers, care providers and local decision makers and to present the prototype web tool, soliciting feedback on how it might be refined or extended to enhance its usefulness for different potential users.

\section{Mortality model}

An alternative to an indicator approach to vulnerability assessment is impact modelling (see "Box 1"), and mortality is a definitive impact with a well-established historical relationship to extreme temperature, especially among the elderly population (e.g., Keatinge et al. 2000). A regression model for Finland was fitted to mortality statistics for hospital districts and regionally-averaged daily temperatures over the period 1971-2010:

$y_{\mathrm{i}}=\left\{\begin{array}{cc}y_{\mathrm{b}} \mathrm{e}^{a\left(T_{\mathrm{i}}-T_{\mathrm{b}}\right)}, & T_{\mathrm{i}}>T_{\mathrm{b}} \\ y_{\mathrm{b}}, & T_{\mathrm{i}} \leq T_{\mathrm{b}}\end{array}\right.$

where $y_{\mathrm{i}}$ is total daily mortality, $T_{\mathrm{i}}$ is daily mean temperature, $a$ is a coefficient and $T_{\mathrm{b}}$ is an empirically derived base temperature at which minimum mortality $\left(y_{\mathrm{b}}\right)$ occurs. Annual heat-related mortality is then:

$y^{\prime}=\sum_{i=1}^{365} y_{\mathrm{i}}-y_{\mathrm{b}}$

Note that because of the small and relatively sparse Finnish population, parameters for the model were determined for the whole population, though it is known that a large majority of temperature-related deaths, especially under extreme temperature conditions, are observed among the elderly. The model was next used to predict mortality for observed daily temperatures adjusted according to different future projections. Estimates of mortality rates above the base mortality (per 100,000 persons) were then converted to absolute values by using population statistics for each municipality.

\section{Results}

Feedback on the mapping tool

All participants at the Stockholm workshop were invited to provide feedback on the usefulness and usability of the prototype mapping tool. The tool was regarded as a visually attractive, colourful and useful device for raising awareness of climate change vulnerability. In general, maps were seen as a good way of communicating aspects of climate change vulnerability to planners, who are accustomed to reading maps and use them in their everyday work. Most of the selected indicators were regarded as useful for describing some issues of vulnerability.

It was observed that enhancing the proportion of elderly receiving home health care might be expected to increase adaptive capacity (e.g., wealthier municipalities being able to offer improved home care), rather than decreasing it as is found in the default setting, which equates increased care to poorer conditions of the elderly (Table 1). This ambiguity is now addressed through an option to reverse the direction of effect on vulnerability from a default case.

The municipality-scale information that is provided on the mapping tool was thought to be useful on national to regional scales. However, planners of cities or municipalities would require more spatial detail for their decisions and options for selecting information for individual cities might be an interesting addition to the tool. Other suggestions for enhancing the tool, aspects of which have been implemented in Step 5, included:

- offering information on adaptation options relevant to the vulnerabilities being mapped;

- indicating the locations and distributions of various key stakeholder organisations that could be contacted for possible follow-up actions;

- mentioning the limitations of the data presented, in order to avoid too strict interpretation of the results;

- putting in place a means for updating indicator data in the future.

\section{Interview results}

Several factors were identified by interviewees in Finland and Sweden as increasing the vulnerability of the elderly. Those elderly persons suffering from conditions such as cardiovascular and respiratory illnesses, weakening of cognitive abilities or depression as well as those experiencing a poor economic situation, living alone and with few social contacts were seen as especially vulnerable to the impacts of climate change.

Some of the key findings distilled from the sample interviews included:

- A general awareness of the threats that heat waves pose for elderly people.

- Recognition of increasing risks of storms, extreme snowfall and power cuts and their effects, especially in rural areas.

- The injury risk of slippery streets was not as clearly connected with climate change and was seen more as a question of street maintenance by respondents in Finland, though accidents involving falling among the 
elderly was recognised in a climate change context by interviewees in Sweden.

- Climate change impacts had not been taken into account systematically at a planning and strategic level in the interviewees' organisations.

Some future developments within elderly care that can have interactions with climate change were recognised. The dependency ratio between numbers of elderly and people of working age is changing and there will be fewer people available to take care of a growing number of elderly in the future. A larger share of the elderly is also expected to be living at home, which is government policy in most Nordic countries (e.g., see targets for Finland in STM 2008). Living at home can increase the vulnerability of elderly people to heat waves and other weather events. It was also mentioned that there is a risk of growing polarisation in the quality of care provision among the elderly population as well as a widening gulf between municipalities.

Examples of potential adaptation measures that were brought up by the interviewees include:

- Raising awareness of extreme weather events and their impacts on the elderly.

- Promotion of a social, healthy and active lifestyle for all (public health).

- A more communal way of living.

- Introducing "social janitors" in blocks of flats.

- Planning of future urban environments to account for the needs of the elderly.

Some of these measures have been included as supporting information in a revised version of the web tool.

\section{Projected mortality}

The mortality-temperature model described in "Mortality model" was used to estimate regional mortality rates across Finland under present-day observed (1971-2000) and future projected (2020-2049) climates. Observational daily temperature data were available for a regular $10 \mathrm{~km}$ grid over Finland (Jylhä et al. 2009). These were then adjusted to represent a range of uncertainties in GCM projections for 2020-2049 (see "Projecting future vulnerability"). Mortality rates were computed by grid box and then averaged across municipalities. Results indicate that while mortality rates are projected to increase in all municipalities under the three projected climates (Fig. 3a-c), total heat-related deaths may actually decrease in some regions due to population decline (Fig. 3d-f). The results assume unchanged sensitivity of mortality to temperature in the future, and work in progress seeks to refine the temperature-mortality model.

\section{Discussion}

This paper has detailed recent and ongoing research that aims to draw attention to the risks of climate change for the elderly population in the Nordic region and the possible need for adaptation responses. A key outcome of the research is the development of an interactive web-based tool for mapping and combining indicators of climate change vulnerability of the elderly, by municipality, across the three Nordic countries: Finland, Norway and Sweden. The tool can also be used for projecting temperature-related mortality in Finland under different projections of future climate, and for depicting background information on potential measures for adapting to more frequent and severe heat waves.

The value of a prototype version of the tool as an awareness-raising device was confirmed at a stakeholder workshop, though modifications and extensions were also proposed by care providers and other persons concerned with the well being of the elderly. Some of these suggestions have been implemented in an updated version of the tool. Of the many insights obtained from this research, six are highlighted in the following sub-sections.

\section{A shift in the onus of analysis and interpretation}

In spite of the normative aspects of indicator analysis and mapping, rightly critiqued in earlier reviews (see "Vulnerability mapping"), the experience gained from this study suggests that there can be value in presenting such information in a tool of this kind, as long as proper documentation is provided along with appropriate caveats to emphasise the subjective nature of the mapping exercise and to caution against over- or misinterpretation. Some of the indicators included, such as weather extremes, are not commonly available at municipality scale. Moreover, this is a first attempt to bring together exposure/sensitivity and adaptive capacity indicators relating to climate change vulnerability of the elderly across the region. The tool is interactive and indicators are clearly documented and can be presented in their original measurement units. Most importantly, perhaps, it is users rather than researchers (as in most previous studies) who determine the indicators and indices selected and mapped. It was encouraging that the stakeholders consulted in this work responded both positively as well as critically to the opportunities presented by the tool, and considered it as potentially offering new and useful information that they might not otherwise have been able to access.

Perceptions of vulnerability

The indicators of adaptive capacity selected for this study all reflect tangible attributes, such as economic resources, 


\section{Change in mortality rate per 100,000 (2020-2049 climate)}

(a) B1, $5^{\text {th }}$ percentile

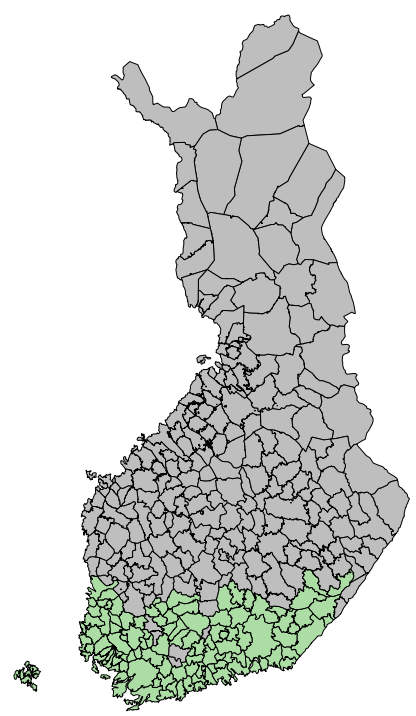

(b) A1B, median

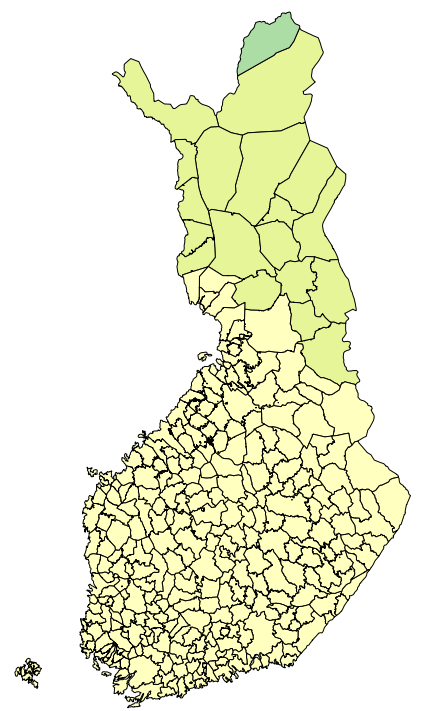

(c) $\mathrm{A} 2,95^{\text {th }}$ percentile

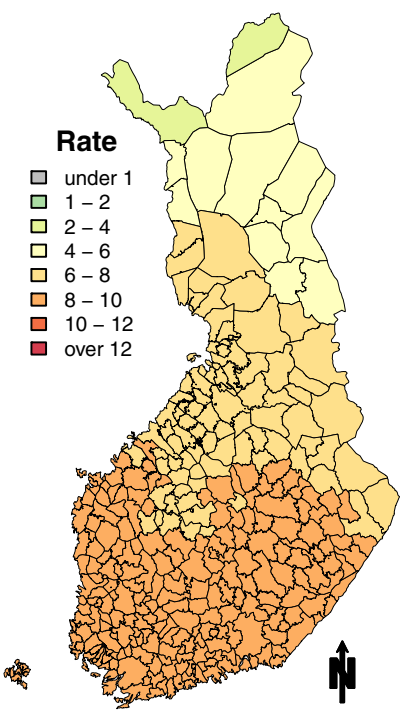

Change in mortality (2020-2049 climate; 2040 population)

(d) $\mathrm{B} 1,5^{\text {th }}$ percentile

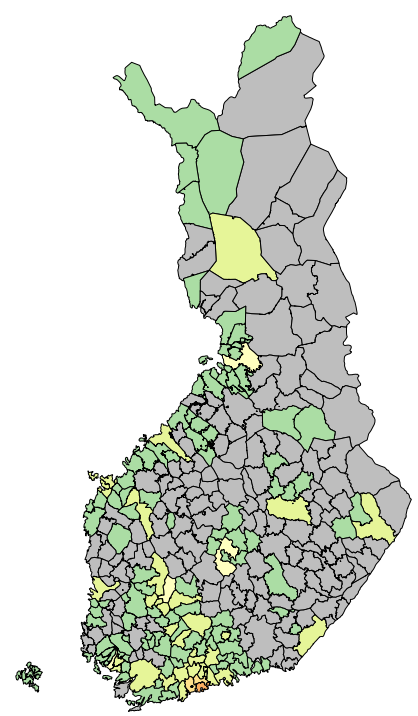

(e) A1B, median

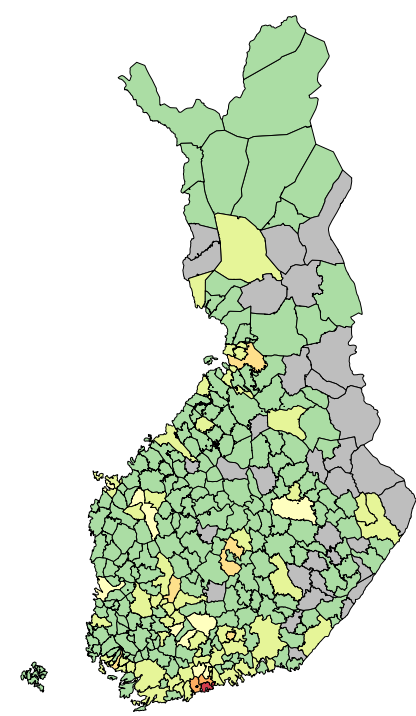

(f) A2, $95^{\text {th }}$ percentile

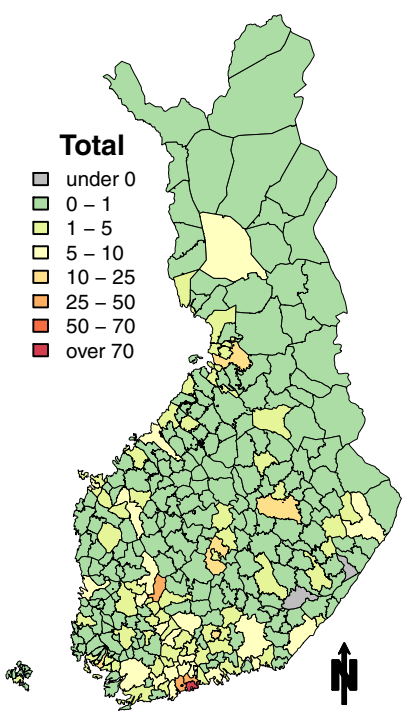

Fig. 3 Modelled change in average annual mortality by municipality for climate change projected between 1971-2000 and 2020-2049 expressed as rates per 100,000 (a-c) and as totals using projected 2040 population $(\mathbf{d}-\mathbf{f})$. Climate projections are 19-member ensemble

social provision and accessibility. However, these indicate only the potential material capacity of populations to adapt to a changing climate, and this may not reflect the reality of adaptive behaviour. This paper has suggested how potential adaptation (adaptive capacity) might be translated-analytically—into actual adaptation (see "Box 1"). However, mediating this translation, the uptake of adaptation is strongly affected by individuals' perceptions of their
GCM results over Finland for SRES emissions: 5th percentile for B1 (low) emissions (a, d), median for A1B (intermediate) emissions (b, e), and 95th percentile for A2 (high) emissions (c, f). Population projections for 2040 are from Statistics Finland

vulnerability to climate change. These characteristics are highly subjective and difficult to measure. A useful illustration of this is a study of Norwegian elderly living in Spain (Ruud 2010). Here, respondents to an interview survey did not necessarily perceive themselves either as vulnerable to heat waves or as being elderly, even if according to objective measures they might be regarded as both. Though they are objectively more at risk of adverse 
effects in the warmer Spanish climate than in Norway, unless they had actually experienced the ill-effects of heat stress many were unaware or sceptical of such impacts.

\section{Limitations of the mapping tool}

The mapping tool presents information primarily at the scale of municipalities. This is helpful for comparison at regional, national and trans-national scales, but is of limited use for stakeholders working at municipal scale, who would require finer-scale mapping of relative vulnerability in order to target adaptation. One constraint on fine grained analysis (e.g., of different age cohorts) is the small size and fluid structure of populations in many rural municipalities in the region. However, follow-up studies might be feasible in urban centres, applying more detailed statistical data on demographic and socioeconomic indicators, or considering other aspects of exposure, such as microclimatic conditions associated with the urban heat island effect (e.g., Suomi et al. 2012). The variables chosen as indicators were also limited to those for which data were available across all three Nordic countries, though the number could be expanded for any individual country. New common indicators could also be added in future. For example, one indicator of the general health of the population, and its likely sensitivity to weather effects for any particular age cohort, could be life expectancy.

Another potential limitation of the tool concerns the linear scaling method of normalisation used to combine indicators. This can be problematic for indicators with skewed distributions, where disproportionate weight might be given to municipalities with extreme values. For instance, the receipt of home health care provision across the region is positively skewed, with the service available to less than $10 \%$ of the elderly in the great majority of municipalities, while over $20 \%$ have access in just a few. Here, a transformation of the data might be worthy of consideration. Moreover, an assumption underpinning the additive averaging procedure used to combine indicators into exposure and adaptive capacity indices, and to combine these indices into a vulnerability index (in Eq. 4b), is that each indicator (or index) is fully substitutable for any other (see discussion in Tol and Yohe 2007). This restriction can be overcome to some degree in the tool by assigning subjective weights to individual indicators, though the composite indices $E^{*}$ and $A^{*}$ are currently assigned equal weights.

\section{Specifying future conditions}

The future predisposition of the elderly to climate change will be conditioned as much by ongoing socioeconomic trends as by changes in physical hazards (see Eq. 7, "Box
1"). The challenge of projecting socioeconomic conditions over multi-decadal time horizons into the future may have deterred many analysts in the past from incorporating such scenarios in vulnerability indices alongside projections of future climate. However, there can be value in exploring the relative sensitivity of vulnerability indices to plausible future trends in different socioeconomic indicators, and an attempt is made in this study to specify upper and lower bounds on the extrapolation of historical time series. The uncertainties surrounding all projections merit close attention, and many of the revisions of the tool focused on representing these by way of alternative scenarios as well as probabilistic projections. Future elaborations might take in regional manifestations of a new set of shared socioeconomic pathways (SSPs) being developed to supersede the SRES scenarios (Moss et al. 2010; O'Neill et al. 2014).

\section{Modelling mortality and other impacts}

One of the new avenues pursued in Step 5 of the study was work to develop impact models relating temperature to mortality in Finland (paralleling similar modelling work conducted during the past decade in Sweden, e.g., Rocklöv and Forsberg 2008, 2009) and using these to project regional variations in Finnish mortality. Definitive rather than indicative estimates of impacts, such as mortality and morbidity, whether for the elderly or for the population as a whole, raise the prospect of being able to evaluate the potential economic and social costs to society of climate change impacts on human health, building on earlier work in Europe (e.g., Watkiss et al. 2010).

\section{Addressing practical adaptation measures}

Some potential adaptation measures for improving the capacity of the elderly to cope with changes in extreme weather associated with climate change are detailed in "Projected mortality", above. However, this list is only indicative, stimulated by a direct request for more information on adaptation options and based on a limited set of interviews with care providers conducted near the end of the study. The compilation of a more comprehensive set of measures, including suggestions for (or real world examples of) their effective implementation, is a clear priority for follow-up work, through engagement with a wider range of relevant stakeholders as well as more in depth literature review. Such new information can then be integrated into the web tool.

Finally, the ultimate test of the tool's utility is its application by various users, and future activities could helpfully include a stakeholder-orientated evaluation of its usefulness and relevance to practical adaptation as well as 
its broader value for education and awareness-raising. There is a broad literature on the shortcomings of research for societal application, pointing in general to differences in values, reward systems and language between the research and policy communities (e.g., Caplan 1979), and in particular to an information "usability" gap in the climate change arena (e.g., Kirchhoff et al. 2013; Moser and Boycoff 2013; Moss et al. 2013). In order to remedy this, there have been efforts to monitor and evaluate research performance (e.g., Boaz et al. 2008), including research on climate change adaptation (e.g., Bours et al. 2013). In this context, there are challenges associated with evaluating, on the short time scales of most research projects, impacts of initiatives with intended long-term adaptation goals, such as this web tool. Bours et al. (2013) describe "process" indicators that can be used to measure steps along a visualised pathway of change towards an intended outcome, which they regard as essential for enabling adaptation learning and improvement, and which might offer a useful starting point for any follow-up study.

\section{Box 1 Reconciling impact and vulnerability approaches}

A future impact of climate change $(I)$ can be expressed as a function of exposure $(E)$ of the system or process to the change in climate and its sensitivity to that change $(S)$ :

$I=f(E, S)$.

This term is sometimes referred to as potential impact (Metzger et al. 2008), as it does not account for likely modifications of the exposure and sensitivity terms (and hence the impact) as climate changes (e.g., through adaptation). Impact responses are commonly estimated using formal mathematical models, where causal relationships are represented in a system of equations. However, where such causal models do not exist, more descriptive models, such as indices, may also be applied.

Exposure is a function of the magnitude of climate change $(\Delta C)$-which can refer to climate as well as associated variables such as atmospheric composition or sea level-and the location or circumstances of the system or process with respect to the climate change $(U)$ :

$E=f(\Delta C, U)$.

Sensitivity refers to the impact response per unit of climate change moderated by a given circumstance:

$S=I / \Delta C_{U}$.

Exposure and sensitivity are crucial terms for considering adaptation (see below).

The definition of vulnerability to climate change $(V)$ commonly applied for developing indices is given by IPCC
(2007, p. 21) as a function of exposure, sensitivity and adaptive capacity $\left(A^{*}\right)$ of the system or process:

$V=f\left(E, S, A^{*}\right)$.

This formulation is an extension of (1), where the introduction of adaptive capacity is a way of bridging between future impact and vulnerability. Both vulnerability and adaptive capacity refer to potential rather than realised outcomes (in the absence of data to describe these and/or causal models to relate them). Vulnerability is an estimate of the propensity to be adversely impacted (IPCC 2012) rather than an estimate of actual impact to be expected. Similarly, adaptive capacity describes the potential for adaptation based on the resources available, rather than the actual readiness and ability to adapt. Note also that vulnerability alludes to detrimental impacts, whereas some impacts may in fact be beneficial.

In order to progress from vulnerability shown in (4) towards realised impacts requires that the exposure and sensitivity terms in (1) be modified. For exposure (2), the climate change term can be altered through mitigation $\left(\Delta C_{\mathrm{M}}\right)$. The circumstances in which the climate change is experienced $(U)$ can also be modified. There are two ways that this might happen: first, through general socioeconomic trends $(\tau)$ that continually alter the circumstances of populations or systems (e.g., demographic change, urbanisation, land use change), and second, by adaptation (A) that aims to alter circumstances to provide benefits with respect to climate change (e.g., building dykes, planning green spaces, or altering forestry rotation times):

$E^{\prime}=f\left(\Delta C_{\mathrm{M}}, U_{\tau, \mathrm{A}}\right)$.

Sensitivity (3) can also be altered in two ways: first, through general socioeconomic trends $(\tau)$ that may alter the intrinsic sensitivity of a system exposed to climate change (e.g., people are less physiologically sensitive today to extreme temperatures than people of the same age in previous decades, due to general enhancements in health and overall life expectancy), and second, by adaptation (A) that targets intrinsic properties of a system's sensitivity to climate (e.g., through technological means like breeding for high temperature or drought tolerance in plants, or through social measures such as awareness-raising or emergency preparedness): $S^{\prime}=f\left(S_{\tau, \mathrm{A}}\right)$.

By inserting expressions (5) and (6) into (1), the adaptive capacity term in (4) is operationalized into concrete adaptation measures:

$I=f\left(\Delta C_{\mathrm{M}}, U_{\tau, \mathrm{A}}, S_{\tau, \mathrm{A}}\right)$.

Here future impacts are a function of the climate change (mitigated to a greater or lesser extent) mediated by future trends and targeted adaptations that modify both 


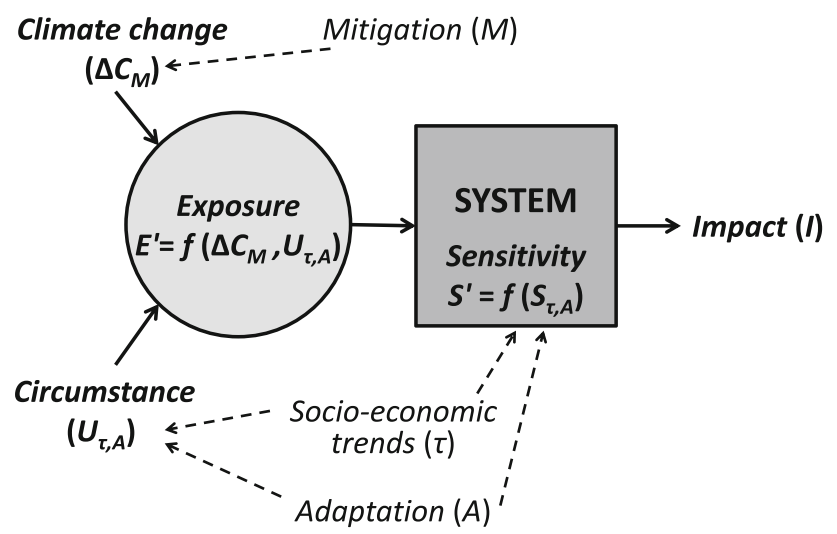

Fig. 4 The impact of climate change on a system as a function of exposure and sensitivity (schematic)

circumstantial exposure and intrinsic sensitivity. These formulations are illustrated in Fig. 4.

It is interesting to reflect that while the large majority of index-based vulnerability studies address the changing climate using future scenarios, very few use scenarios to specify the four other terms, instead fixing them at presentday reference levels. In other words, vulnerability to a changed climate is commonly being assessed assuming no future change in circumstances, sensitivity or adaptive capability (and see Preston et al. 2011). Notable exceptions include work on ecosystem service vulnerability (Schröter et al. 2005; Acosta et al. 2013) and coastal zone vulnerability (Nicholls et al. 2008).

Acknowledgments The authors are very grateful to Ida Skivenes and Cathrine Ruud of the University of Oslo, for contributing to the literature survey, data collection and analysis, and to colleagues in the MEDIATION project for providing helpful feedback on the web tool. The incisive comments of two anonymous reviewers were also much appreciated. This work was conducted as part of three projects: CARAVAN (Climate change: a regional assessment of vulnerability and adaptive capacity for the Nordic countries), funded by the Academy of Finland, Research Council of Norway and Swedish Environmental Protection Agency in the Nordic-Call of CIRCLE (Climate Impact Research Coordination for a Larger Europe), an ERA-Net project established under the European Commission Sixth Framework Programme, MAVERIC (Map-based assessment of vulnerability to climate change employing regional indicators) project, funded by the Academy of Finland, and MEDIATION (Methodology for Effective Decision-making on Impacts and AdaptaTION), funded by the European Commission, Seventh Framework Programme.

Open Access This article is distributed under the terms of the Creative Commons Attribution License which permits any use, distribution, and reproduction in any medium, provided the original author(s) and the source are credited.

\section{References}

Acosta L, Klein RJT, Reidsma P, Metzger MJ, Rounsevell MDA, Leemans R, Schröter D (2013) A spatially explicit scenario- driven model of adaptive capacity to global change in Europe. Glob Environ Change doi:10.1016/j.gloenvcha.2013.03.008

Alho JM, Spencer BD (1985) Uncertain population forecasting. J Am Stat Assoc 80:306-314

Alho JM, Spencer BD (1997) The practical specification of the expected error of population forecasts. J Off Stat 13:203-225

Åström C, Orru H, Rocklöv J, Strandberg G, Ebi KL, Forsberg B (2013) Heat-related respiratory hospital admissions in Europe in a changing climate: a health impact assessment. BMJ Open. doi:10.1136/bmjopen-2012-001842

Barriopedro D, Fischer EM, Luterbacher J, Trigo RM, García-Herrera R (2011) The hot summer of 2010: redrawing the temperature record map of Europe. Science 332:220-224

Beniston M, Stephenson DB, Christensen OB, Ferro CAT, Frei C, Goyette S, Halsnaes H, Holt T, Jylhä K, Koffi B, Palutikof J, Schöll R, Semmler T, Woth K (2007) Future extreme events in European climate: an exploration of regional climate model projections. Clim Change 81:71-95

Boaz A, Fitzpatrick S, Shaw B (2008) Assessing the impact of research on policy: a review of the literature for a project on bridging research and policy through outcome evaluation. Report to Defra, King's College London and Policy Studies Institute, p 26

Bours D, McGinn C, Pringle P (2013) Monitoring and evaluation for climate change adaptation: a synthesis of tools, frameworks and approaches. SEA Change Community of Practice, Phnom Penh and UKCIP, Oxford, p 67

Caplan N (1979) The two-communities theory and knowledge utilization. Am Behav Sci 22:459-470

Carter TR, Fronzek S, Mela H, O'Brien K, Rosentrater L, Simonsson L (2011) Climate change vulnerability mapping for the nordic region: CARAVAN/MEDIATION Joint Workshop, Stockholm, 9 November 2010, Summary Report. MEDIATION Milestone Report 5a. Finnish Environment Institute (unpublished mimeo), p 12

Diffenbaugh NS, Giorgi F, Raymond L, Bi X (2007) Indicators of 21 st century socioclimatic exposure. Proc Natl Acad Sci 104:20195-20198

Flinkkilä T, Sirniö K, Hippi M, Hartonen S, Ruuhela R, Ohtonen P, Hyvönen P, Leppilahti J (2010) Epidemiology and seasonal variation of distal radius fractures in Oulu, Finland. Osteoporos Int 22:2307-2312

Frich P, Alexander LV, Della-Marta PM, Gleason B, Haylock M, Klein Tank AMG, Peterson T (2002) Observed coherent changes in climatic extremes during the second half of the twentieth century. Clim Res 19:193-212

Füssel H-M (2010a) How inequitable is the global distribution of responsibility, capability, and vulnerability to climate change: a comprehensive indicator-based assessment. Glob Environ Change 20:597-611

Füssel H-M (2010b) Review and quantitative analysis of indices of climate change exposure, adaptive capacity, sensitivity, and impacts. Background note to the World Development Report 2010. World Bank, Washington, DC, p 34

Füssel H-M, Klein RJT (2006) Climate change vulnerability assessments: an evolution of conceptual thinking. Clim Change 75:301-329

Greiving S, Flex F, Lindner C, Lückenkötter J, Schmidt-Thomé P, Klein J, Tarvainen T, Jarva J, Backman B, Luoma S, Langeland O, Langset B, Medby P, Davoudi S, Tranos E, Holsten A, Kropp J, Walter C, Lissner T, Roithmeier O, M. K, Juhola S, P. N, Peltonen L, Vehmas J, Sauri D, Serra A, Olcina J, March H, Martín-Vide J, Vera F, Padilla E, Serra-Llobet A, Csete M, Pálvölgyi T, Göncz A, Király D, Schneller K, Staub F, Peleanu I, Petrisor A-I, Dzurdzenik J, Tesliar J, Visy E, Bouwman A, Knoop J, Ligtvoet W, van Minnen J, Kruse S, Pütz M, Stiffler M, 
Baumgartner D (2011) ESPON Climate: Climate Change and Territorial Effects on Regions and Local Economies. Scientific Report, ESPON \& IRPUD, TU Dortmund University, Germany, p 291

Harris GR, Collins M, Sexton DMH, Murphy JM, Booth BBB (2010) Probabilistic projections for 21 st century European climate. Nat Hazards Earth Syst Sci 10:2009-2020

Haylock MR, Hofstra N, Klein Tank AMG, Klok EJ, Jones PD, New M (2008) A European daily high-resolution gridded data set of surface temperature and precipitation for 1950-2006. J Geophys Res Atmosphere 113:D20119. http://eca.knmi.nl/download/ ensembles/ensembles.php

Hinkel J (2011) Indicators of vulnerability and adaptive capacity: towards a clarification of the science-policy interface. Glob Environ Change 21:198-208

IPCC (2007) Summary for policymakers. In: Climate change 2007: impacts, adaptation and vulnerability. In: Parry ML, Canziani OF, Palutikof JP, van der Linden PJ, Hanson CE (eds) Contribution of Working Group II to the Fourth Assessment Report of the Intergovernmental Panel on Climate Change. Cambridge University Press, Cambridge, pp 7-22

IPCC (2012) Glossary of terms. In: Managing the risks of extreme events and disasters to advance climate change adaptation. In: Field CB, Barros V, Stocker TF, Qin D, Dokken DJ, Ebi KL, Mastrandrea MD, Mach KJ, Plattner G-K, Allen SK, Tignor M, Midgley PM (eds) A Special Report of Working Groups I and II of the Intergovernmental Panel on Climate Change. Cambridge University Press, Cambridge, pp 555-564

Jylhä K, Ruosteenoja K, Räisänen J, Venäläinen A, Tuomenvirta H, Ruokolainen L, Saku S, Seitola T (2009) The changing climate in Finland: estimates for adaptation studies: ACCLIM project report 2009. Finnish Meteorological Institute, Reports 2009:4, Helsinki, Finland (in Finnish, extended abstract and figure captions also in English), p 102

Keatinge WR, Donaldson GC, Cordioli E, Martinelli M, Kunst AE, Mackenbach JP, Näyhä S (2000) Heat related mortality in warm and cold regions of Europe: observational study. Br Med J 321:670-673

Kirchhoff CJ, Lemos MC, Dessai S (2013) Actionable knowledge for environmental decision making: broadening the usability of climate science. Annu Rev Environ Resour 38:393-414

Koppe C, Kovats S, Jendritzky G, Menne B (2004) Heat-waves: risks and responses. Health and Global Environmental Change Series, No. 2. World Health Organization Regional Office for Europe, Copenhagen, p 123

Lavell A, Oppenheimer M, Diop C, Hess J, Lempert R, Li J, MuirWood R, Myeong S (2012) Climate change: new dimensions in disaster risk, exposure, vulnerability, and resilience. In: Field CB, Barros V, Stocker TF, Qin D, Dokken DJ, Ebi KL, Mastrandrea MD, Mach KJ, Plattner G-K, Allen SK, Tignor M, Midgley PM (eds) Managing the risks of extreme events and disasters to advance climate change adaptation. A Special Report of Working Groups I and II of the Intergovernmental Panel on Climate Change (IPCC). Cambridge University Press, Cambridge, pp 25-64

Le Tertre A, Lefranc A, Eilstein D, Declercq C, Medina S, Blanchard M, Chardon B, Fabre P, Filleul L, Jusot J-F, Pascal L, Prouvost H, Cassadou S, Ledrans M (2006) Impact of the 2003 heatwave on all-cause mortality in 9 French cities. Epidemiology 17:75-79

Loughnan ME, Tapper NJ, Phan T, Lynch K, McInnes JA (2013) A spatial vulnerability analysis of urban populations during extreme heat events in Australian capital cities. National Climate Change Adaptation Research Facility, Gold Coast, Australia, p 128

Lung T, Lavalle C, Hiederer R, Dosio A, Bouwer LM (2013) A multihazard regional level impact assessment for Europe combining indicators of climatic and non-climatic change. Glob Environ Change 23:522-536

Malone EL, Engle NL (2011) Evaluating regional vulnerability to climate change: purposes and methods. Wiley Interdiscip Rev Clim Change 2:462-474

Metzger MJ, Schröter D, Leemans R, Cramer W (2008) A spatially explicit and quantitative vulnerability assessment of ecosystem service change in Europe. Reg Environ Change 8:91-107

Moser SC, Boycoff MT (eds) (2013) Successful adaptation to climate change: linking science and policy in a rapidly changing world, Routledge, p 360

Moss RH, Edmonds JA, Hibbard K, Manning M, Rose SK, van Vuuren DP, Carter TR, Emori S, Kainuma M, Kram T, Meehl G, Mitchell J, Nakicenovic N, Riahi K, Smith S, Stouffer RJ, Thomson A, Weyant J, Wilbanks T (2010) The next generation of scenarios for climate change research and assessment. Nature 463:747-756

Moss RH, Meehl GA, Lemos MC, Smith JB, Arnold JR, Arnott JC, Behar D, Brasseur GP, Broomell SB, Busalacchi AJ, Dessai S, Ebi KL, Edmonds JA, Furlow J, Goddard L, Hartmann HC, Hurrell JW, Katzenberger JW, Liverman DM, Mote PW, Moser SC, Kumar A, Pulwarty RS, Seyller EA, Turner BL II, Washington MW, Wilbanks TJ (2013) Hell and high water: practice-relevant adaptation science. Science 342:696-698

Näyhä S (2005) Environmental temperature and mortality. Int J Circumpolar Health 64:451-458

Nicholls RJ, Wong PP, Burkett V, Woodroffe C, Hay J (2008) Climate change and coastal vulnerability assessment: scenarios for integrated assessment. Sustain Sci 3:89-102

O'Brien K, Leichenko R (2007) Human security, vulnerability and sustainable adaptation. Human Development Report 2007/2008, Occasional Paper. United Nations Development Programme, New York, p 47

O'Brien K, Leichenko R, Kelkar U, Venema H, Aandahl G, Tompkins H, Javed A, Bhadwal S, Barg S, Nygaard L, West J (2004a) Mapping vulnerability to multiple stressors: climate change and globalization in India. Glob Environ Change 14:303-313

O'Brien K, Sygna L, Haugen JE (2004b) Vulnerable or resilient? A multi-scale assessment of climate impacts and vulnerability in Norway. Clim Change 64:193-225

O’Brien K, Eriksen S, Sygna L, Naess LO (2006) Questioning complacency: climate change impacts, vulnerability, and adaptation in Norway. Ambio 35:50-56

OECD (2006) Sweden: safety of the elderly. OECD studies in risk management. Organisation for Economic Co-operation and Development, Paris, p 74

O’Neill MS, Carter R, Kish JK, Gronlund CJ, White-Newsome JL, Manarolla X, Zanobetti A, Schwartz JD (2009) Preventing heatrelated morbidity and mortality: new approaches in a changing climate. Maturitas 64:98-103

O’Neill BC, Kriegler E, Riahi K, Ebi KL, Hallegatte S, Carter TR, Mathur R, van Vuuren DP (2014) A new scenario framework for climate change research: the concept of shared socioeconomic pathways. Clim Change 122:387-400

Patt AG, Schröter D, de la Vega-Leinert AC, Klein RJT (2009) Vulnerability research and assessment to support adaptation and mitigation: common themes from a diversity of approaches. In Patt AG, Schröter D, Klein RJT, de la Vega-Leinert AC (eds) Assessing vulnerability to global environmental change. Making research useful for adaptation decision making and policy. Earthscan, London, pp 1-25

Polsky C, Neff R, Yarnal B (2007) Building comparable global change vulnerability assessments: the vulnerability scoping diagram. Glob Environ Change 17:472-485 
Preston BL, Yuen EJ, Westaway RM (2011) Putting vulnerability to climate change on the map: a review of approaches, benefits, and risks. Sustain Sci 6:177-202

Reid CE, Mann JK, Alfasso R, English PB, King GC, Lincoln RA, Margolis HG, Rubado DJ, Sabato JE, West NL, Woods B, Navarro KM, Balmes JR (2012) Evaluation of a heat vulnerability index on abnormally hot days: an environmental public health tracking study. Environ Health Perspect 120:715-720

Robine J-M, Cheung SLK, Roy SL, Oyen HV, Griffiths C, Michel J-P, Herrmann FR (2008) Death toll exceeded 70,000 in Europe during the summer of 2003. CR Biol 331:171-178

Rocklöv J, Forsberg B (2008) The effect of temperature on mortality in Stockholm 1998-2003: a study of lag structures and heatwave effects. Scand J Pub Health 36:516-523

Rocklöv J, Forsberg B (2009) Comparing approaches for studying the effects of climate extremes: a case study of hospital admissions in Sweden during an extremely warm summer. Global Health Action. doi:10.3402/gha.v2i0.2034

Rød JK, Berthling I, Lein H, Lujala P, Vatne G, Bye LM (2012) Integrated vulnerability mapping for wards in Mid-Norway. Local Environ 17:695-716

Rothman DS, Robinson JB (1997) Growing pains: a conceptual framework for considering integrated assessments. Environ Monit Assess 46:23-43

Ruud C (2010) "Vi har det fint her nede". Klimasårbarhet blant norske eldre-oppfatninger av klimaendringer og implikasjonene for tilpasning ("We're doing well down here". Climate vulnerability among ageing Norwegians-perceptions of climate change and the implications for adaptation). Master Thesis in Human Geography (SGO4090). Department of Sociology and Human Geography, University of Oslo, p 123

Ruuhela R (ed) (2012) Miten väistämättömään ilmastonmuutokseen voidaan varautua? Yhteenveto suomalaisesta sopeutumistutkimuksesta eri toimialoilla. (How can we prepare for unavoidable climate change? Summary report of Finnish adaptation research in different sectors), Publications of the Ministry of Agriculture and Forestry 6/2011, Helsinki, p 177

Ruuhela R, Ruotsalainen J, Kangas M, Aschan C, Rajamäki E, Hirvonen M, Mannelin T (2005) Kelimallin kehittäminen talvijalankulun turvallisuuden parantamiseksi: Loppuraportti (Predicting wintertime pavement conditions for the safety of pedestrians: Final report). Helsinki, Finnish Meteorological Institute Reports vol 1, p 47 (in Finnish with English abstract)

Schröter D, Cramer W, Leemans R, Prentice IC, Araújo MB, Arnell NW, Bondeau A, Bugmann H, Carter TR, Garcia CA, de la Vega-Leinert AC, Erhard M, Ewert F, Glendining M, House JI, Kankaanpää S, Klein RJT, Lavorel S, Lindner M, Metzger MJ, Meyer J, Mitchell TD, Reginster I, Rounsevell M, Sabaté S, Sitch S, Smith B, Smith J, Smith P, Sykes MT, Thonicke K, Thuiller W, Tuck G, Zaehle S, Zierl B (2005) Ecosystem service supply and vulnerability to global change in Europe. Science 310:1333-1337

Seneviratne SI, Nicholls N, Easterling D, Goodess CM, Kanae S, Kossin J, Luo Y, Marengo J, McInnes K, Rahimi M, Reichstein M, Sorteberg A, Vera C, Zhang X (2012) Changes in climate extremes and their impacts on the natural physical environment. In: Field CB, Barros V, Stocker TF, Qin D, Dokken DJ, Ebi KL, Mastrandrea MD, Mach KJ, Plattner G-K, Allen SK, Tignor M, Midgley PM (eds) Managing the risks of extreme events and disasters to advance climate change adaptation. A Special Report of Working Groups I and II of the Intergovernmental Panel on Climate Change (IPCC). Cambridge University Press, Cambridge, pp 109-230

Suomi J, Hjort J, Käyhkö J (2012) Effects of scale on modelling the urban heat island in Turku, SW Finland. Clim Res 55:105-118

Swart R, Fons J, Geertsema W, van Hove B, Gregor M, Havranek M, Jacobs C, Kazmierczak A, Krellenberg K, Kuhlicke C, Peltonen L (2012) Urban vulnerability indicators. ETC-CCA and ETCSIA Technical Report 01/2012. European topic centre on climate change impacts, vulnerability and adaptation (ETC CCA) and European topic centre on spatial information and analysis (ETC SIA), p 178

Sygna L, Eriksen S, O'Brien K, Næss LO (2004) Climate change in Norway: analysis of economic and social impacts and adaptations. CICERO Report 2004:12. Center for International Climate and Environmental Research, Oslo, p 40

Terama E, Fronzek S, Mela H, Inkinen A, Lahtinen I, Carter TR (2014) Projecting socioeconomic conditions for exploring future adaptive capacity: a case study in Finland. Draft manuscript available from authors on request

Tol RSJ, Yohe GW (2007) The weakest link hypothesis for adaptive capacity: an empirical test. Glob Environ Change 17:218-227

Venäläinen A, Tuomenvirta H, Pirinen P, Drebs A (2005) A basic Finnish climate data set 1961-2000-description and illustrations. Finnish Meteorological Institute, Reports 5, p 27

von Schirnding Y (2002) Health in sustainable development planning: the role of indicators. World Health Organization, Geneva, p 156

Watkiss P, Horrocks L, Pye S, Searl A, Hunt A (2010) Impacts of climate change in human health in Europe. PESETA-Human health study. JRC Scientific and Technical Reports. European Commission Joint Research Centre, Luxembourg, p 52

Wolf T, McGregor G, Analitis A (2014) Performance assessment of a heat wave vulnerability index for Greater London, United Kingdom. Weather Clim Soc 6:32-46

Yohe G, Malone E, Brenkert A, Schlesinger M, Meij H, Xing X (2006) Global distributions of vulnerability to climate change. Integr Assess J 6:35-44 